\title{
Rehabilitation Process and Persons with Physical Dysfunctions
}

\author{
Nanjwan, Josephine Dasel; Plang, Janet Punyit \\ Department of Vocational and Special Education Faculty of Education University of Calabar, Calabar. \\ Department of Sociology Faculty of Social Sciences University of Jos, Jos.
}

\begin{abstract}
The main purpose of this study is to determine rehabilitation process and persons with physical dysfunctions. To achieve the purpose of this study, three hypotheses were formulated. Ex-post facto research design was adopted for the study. A sample of one hundred persons with disabilities was randomly selected for the study. The selection was done through the simple random sampling technique. This was to give equal and independent opportunity to all the respondents to be selected for the study. The questionnaire was the major instrument used for data collection. The instrument was subjected to both face and content validation by expert in measurement and evaluation. The reliability estimate of the instrument was established through the test-retest reliability method Pearson product correlation analysis and independent $t$-test were employed were adopted to test the hypotheses at .05 level of significance. The result of the analysis reveals that rehabilitation significantly relates with persons with orthopedic and neurological impairments. The result also revealed that there is a significant difference between male and female disabled persons in their perception of rehabilitation of persons with other health impairments.
\end{abstract}

Keywords: Rehabilitation process, persons, physical, dysfunctions.

\section{Introduction}

The loss of any ability results in a sudden restriction in function, sensation and appearance. This can even lead to high levels of frustration due to unmet needs of the client. Most limb amputees have historically been poorly served by rehabilitation service providers in many ways. The volume of services lacked expertise and reliable technology. Most patients have either had no access to a solution or have experience a poor outcome. However, there has been an emergence of improved services and accessibility to international products that can help in rehabilitating person with disability. They can then provide accurate counselling to their patient when faced with difficult situations.

Physical dysfunctions are sub-divided into three major areas namely orthopedic, neurological and other health impairments. The physically impaired individuals are defined as those who have problems of mobility, manual dexterity, and other health impairments which may be congenital or acquired Dunlop (2005) Provision of rehabilitation for persons with special needs requires different rehabilitation process. Ozoji (1993) explained rehabilitation to be the process that leads to the restoration of the disabled to the fullest physical mental, social, vocational and economic usefulness of which they are capable to achieve. It can be seen that without rehabilitation, education of person with special needs may likely be affected in negative ways. The rehabilitation process is different for everyone depending on the impairment and the needs of the individual. Rehabilitation programmes should be individualized, catering to each person's unique needs because no two deformities are exactly alike. Ihenacho (2010). suggested that provision of service to persons with special needs can be done by different categories of people such as: the government, community, private organization and individuals. It embraces the view that any of the categories should be allowed the opportunities to participate in a given rehabilitation programme to person with special needs.

i. Rehabilitation channels the body to natural healing abilities and the brain's relearning processes so that an individual gets relieved as quickly and efficiently as possible.

ii. Rehabilitation also involves learning new ways to compensate for abilities that have permanently changed.

iii. Treatment methods and Technology are rapidly advancing as knowledge of the affected body part and its functions increases (Physical Medicine and Rehabilitation (2010) the goal of rehabilitation is to help people regain the most Independent level of functioning.

\section{Models Of Rehabilitation}

Rehabilitation services for people with different types of physical dysfunction were largely provided in medical facilities with care of physicians, Nurses, and trained professionals. This mode still dominates, but the trend today is toward more community - based rehabilitation models and more options are available than ever before. Rehabilitation service delivery and funding are changing rapidly. Punwar (1994) expressed that working with physically dysfunction persons appear to have increased steadily over the last few years. Many patients who survive from any serious illness become candidate for rehabilitation services. Practitioners who work with 
physical dysfunctions appear to be more specialized in many ways such as: hand, spinal cord injury, burn and other related programmes, are still demanding advance kwoledge and skills. Practice locations for the treatment of physical dysfunctions include: acute care hospitals, rehabilitation centers, nursing homes and extended care facilities, outpatient services and community-based programme.

\section{TYPES OF REHABILITATION}

Management and care continue to replace the traditional-services. Shivers \& Fait (1985) emphasized that rehabilitation involves medical, mental, social, vocational and economic aspects. The author explains that the mental aspect has to do with educating individual through special education where by mental fitness activities will be given to the affected person for example eye- hand coordination activities. Social aspect can be done through planning programmes where by the person is equipped to relate adequately with others. Vocational aspect has to do with training in a competitive skill. Economic aspect is related to essentials for employment of individual either self or government employment. All aspects of that will lead to the employment of person with special needs. This is because opportunities are made accessible to the individual who cannot initially or easily gain access to the available opportunities.

Cratty, (1989) further elaborates the medical aspect in four ways:

i. Medical Based Rehabilitation: Early intervention is crucial. Rehabilitation should ideally start in the intensive care unit. At this point, rehabilitation is generally preventive in nature. Prevention of pressure scores and orientation are very important right from the beginning. Frequently, rehabilitation activities initiated in the Intensive care unit (ICU) can reduce complications and sometimes the length of hospitalization.

ii. Day-treatment-day rehabilitation: Day rehabilitation provides intensive rehabilitation in a structured setting during the day and allows the person with problems to return home to his or her family at night. The treatment team is often made up of a variety of rehabilitation professionals.

iii. Outpatient facilities rehabilitation: Following acute rehabilitation or sub-acute rehabilitation, a person with a physical dysfunction may continue to receive outpatient treatment in specific areas for example, speech pathology to continue to work on speech of the patient. Often, this treatment can also be provided in the home by a Home-health agency.

iv. Transitional living programmes: Transitional living programmes provide housing for persons with special needs, with the goal of regaining the ability to live as independent as possible. Sometimes, programmes will have different levels, depending on the level of need of the individual. In addition to physical, occupational, speech and recreation therapists, these programmes usually need skills therapists who assist the person with a physical dysfunction acquires skills and learn compensatory techniques so that they can live in any independent settings.

\section{IMPORTANCE OF REHABILITATION PROCESS}

Rehabilitation may adopt various forms in handling the individual with physical dysfunctions. These areas may include treatment, education and employment. Treatment may be in the area of therapeutic activities by different professionals such as: physical, occupational and speech therapists (Carte, Nigg \& Hinshaw (1996). Rehabilitation facilitates more participation in workplace activities in the following ways:

1. It also allows more people with disabilities to achieve gainful employment opportunities.

2. Stage of recovery: Developmental levels and goals will vary with the nature of the illness or injury Moreover, people would not have the same progress results from the several therapies they would be undergoing.

Punwar (1994) stated that the goals of rehabilitation programmes may include: restoration or improvement of functional abilities, maintenance of client's abilities at an acceptable levels, the prevention of further disability. Improvement of the client to function in the home and work environment, appropriate environmental adaptations, adjustment of the client to temporary or permanent limitations and resumption of a work or school programme. Treatments, on the other hand, are given according to needs. Despite the condition of the client, therapies would be needed. This would be one aim of the rehabilitation process and that would get back to the person's normal healthy life (Andrews \& Herrelson (1991). Without rehabilitation provision, many persons with special needs will be denied their rights.

It helps in developing economic status and employment opportunities that can enhance their daily living. It enables the individual learn to adjust to be socially mature and face the realities of life. It minimizes the effects of handicaps so that the individual can function well in his or her level. The rehabilitation process requires lots of courage in addition to solving other problems. Be it an actual accident or possibly an issue, the process may indeed concentrate on its goal that might assist the person body get through to the normal functions in the ultimate outcome such as: provision of adequate treatment and education for person special needs based 
on their unique needs. It maintains self realization for better human relationships. It assists handicapped individual have clear perception of the problems and arrive at a realistic adjustment.

\section{STATEMENT OF THE PROBLEM}

It is clear that if the outcome of rehabilitation is poor, it can impose device that has limited use and is inconvenient to the user. Rehabilitation must be addressed by the coordinated involvement of various medical and paramedical disciplines.

1. The rehabilitation process can be difficult to undergo by persons of lower class background due to financial implications.

2. Problems posed by shortage of facilities, equipments and personnel may have negative impact on rehabilitation activities.

3. Rehabilitation activities that involve the selection of an appropriate surgical technique to be employed may be expensive.

4. The rehabilitation duration period if it takes a longer period it will delay the client from participation with their peers.

5. Lack of proper diagnosing of problems create problem of which type of rehabilitation is appropriate for the individual.

6. The patient requires regular and continuous care requirement, maintenance and adjustment to accommodate changes to lifestyle demands or body dimensions.

7. Changes of professionals may be a problem by not knowing the onset of the problems.

8. Where the patient is the primary purchaser of the devices for treatment, the requirement for ongoing costs to maintain the same standard may be a problem.

\section{Methods}

This study adopted the Ex-post facto research design. The target population involved in this study consisted of all persons with physical dysfunctions in Calabar Municipality in Cross River State, Nigeria. A simple random sampling technique was adopted. The research instrument, which was the questionnaire, comprised twenty (20) items, all of the Likert-type 4-point scale (strongly Agree-4 points, Agree-3 points, Disagree 2-points and strongly disagree 1 point). The respondents were required to indicate their level of agreement for each statement.

In terms of validity three experts in educational measurement and evaluation and psychology, affirmed, with $87 \%$ agreement that the entire instrument was suitable for measuring what it purported to measure. Using the test-retest reliability method, the reliability index of the instrument was found to be 0.86 . Data were collected through the use of questionnaire from the sampled institutions used for the study, through the use of the questionnaire from the sampled institution used for the study. Through a very rigorous approach and with the assistance of some persons mainly, to whom the researcher is very grateful, all the 200 copies of the questionnaire were retrieved, and they were all properly completed, thus giving $100 \%$ return rate. The following hypotheses were tested in the study.

1. There is no significant influence of rehabilitation on persons with orthopedic impairments.

2. There is no significant relationship between rehabilitation and persons with neurological impairments.

3. There is no significant difference between male and female disabled persons in their perception of rehabilitation of persons with other health impairments.

\section{Data Analysis}

\section{Hypothesis one}

There is no significant influence of rehabilitation on persons with orthopedic impairments.

The independent variables involve in this hypothesis is rehabilitation, while the dependent variable is persons with orthopedic impairments. Pearson product correlation analysis was employed to test this hypothesis. The result of the analysis is presented in Table 1 .

TABLE 1

Pearson product moment correlation analysis of the relationship between rehabilitation and persons with orthopedic impairments $(\mathbf{N}=100)$

\begin{tabular}{lllll} 
& $\sum \mathrm{x}$ & $\sum \mathrm{x}^{2}$ & & \\
Variables & $\sum \mathrm{y}$ & $\sum \mathrm{y}^{2}$ & $\mathrm{xy}$ & r-value \\
\hline Persons with orthopedic impairments & 1768 & 2637 & & 46741 \\
Rehabilitation & & & 2589 &
\end{tabular}


*Significant at .05 level, critical $\mathrm{r}=.159, \mathrm{df}=98$

The result in Table 1 reveals that the calculated r-value of 0.63 is higher than the critical r-value of .138 at .05 level of significance with 98 degrees of freedom. With this result the null hypothesis was rejected. This result therefore means that there is a significant relationship between rehabilitation and persons with orthopedic impairments.

\section{Hypothesis two}

There is no significant relationship between rehabilitation and persons with neurological impairments.

The independent variables involve in this hypothesis is rehabilitation, while the dependent variable is persons with neurological impairments. Pearson product correlation analysis was employed to test this hypothesis. The result of the analysis is presented in Table 2.

TABLE 2

Pearson product moment correlation analysis of the relationship between rehabilitation and persons with neurological impairments $(\mathrm{N}=100)$

\begin{tabular}{lllll} 
Variables & $\sum \mathrm{x}$ & $\sum \mathrm{x}^{2}$ & & $\mathrm{r}$-value \\
\hline Persons with neurological impairments & $\sum \mathrm{y}$ & $\sum \mathrm{y}^{2}$ & 2843 & \\
Rehabilitation & 1785 & 28338 & $0.58^{*}$ \\
\hline
\end{tabular}

*Significant at .05 level, critical $\mathrm{r}=.195, \mathrm{df}=98$

The result in Table 2 reveals that the calculated r-value of 0.58 is higher than the critical r-value of .195 at .05 level of significance with 198 degrees of freedom. With this result the null hypothesis was rejected. This result therefore means that there is no significant relationship between rehabilitation and persons with neurological impairments.

\section{Hypothesis three}

There is no significant difference between male and female disabled persons in their perception of rehabilitation of persons with other health impairments.

The independent variable in this hypothesis is gender (male and female); while the dependent variable is perception of rehabilitation of persons with other health impairments. To test this hypothesis, perception of rehabilitation of males' and females' persons with other health impairments was compared using Independent t-test analysis. The result of the analysis is presented in Table 3.

TABLE 3

Independent t-test analysis of the difference between male and female persons with other health impairments on their perception of rehabilitation $(\mathrm{N}=\mathbf{2 0 0})$

\begin{tabular}{lcccc}
\hline Gender differences & $\mathrm{N}$ & $\mathrm{N}$ & $\mathrm{S}$ & $\mathrm{t}$-value \\
\hline Male & 55 & 18.29 & 2.13 & $3.19 *$ \\
Female & 45 & 16.82 & 2.42 & \\
\hline
\end{tabular}

The result of the analysis as presented in Table 6 reveals that the calculated t-value of 3.19 is higher than the critical t-value of 1.98 at .05 level of significance with 198 degrees of freedom. With this result, the null hypothesis that there is no significant gender difference in the Legislation of persons with disabilities was rejected. This result indicates that, there is a significant difference between male and female disabled persons in their perception of rehabilitation of persons with other health impairments.

\section{Discussion Of Findings}

The result of the analysis reveals that rehabilitation significantly relate with persons with orthopedic and neurological impairments. The result also revealed that there is a significant difference between male and female disabled persons in their perception of rehabilitation of persons with other health impairments.. The finding is in line with view of Ozoji (1993) who explained rehabilitation to be the process that leads to the restoration of the disabled to the fullest physical mental, social, vocational and economic usefulness of which they are capable to achieve. It can be seen that without rehabilitation, education of person with special needs may likely be affected in negative ways. The rehabilitation process is different for everyone depending on the impairment and the needs of the individual. Rehabilitation programmes should be individualized, catering to each person's unique needs because no two deformities are exactly alike. Ihenacho (2010) also suggested that provision of service to persons with special needs can be done by different categories of people such as: the government, community, private organization and individuals. It embraces the view that any of the categories should be allowed the opportunities to participate in a given rehabilitation programme to person with special needs. 
Physical Medicine and Rehabilitation (2010) also stated that rehabilitation channels the body to natural healing abilities and the brain's relearning processes so that an individual gets relieved as quickly and efficiently as possible. Rehabilitation also involves learning new ways to compensate for abilities that have permanently changed. Treatment methods and Technology are rapidly advancing as knowledge of the affected body part and its functions increases. The goal of rehabilitation is to help people regain the most Independent level of functioning. Punwar (1994) also expressed that working with physically dysfunction persons appear to have increased steadily over the last few years. Many patients who survive from any serious illness become candidate for rehabilitation services. Practitioners who work with physical dysfunctions appear to be more specialized in many ways such as: hand, spinal cord injury, burn and other related programmes, are still demanding advance kwoledge and skills. Practice locations for the treatment of physical dysfunctions include: acute care hospitals, rehabilitation centers, nursing homes and extended care facilities, outpatient services and community-based programme.

\section{Summary/ Conclusion}

Rehabilitation is quite vital to people who have undergone different conditions affecting either physical or mental state of a person. They could even be confined in such facilities either voluntarily or not, as long as the main goal would be recovery. This can actually be achieved with the help of professionals with different skills and techniques from the programmes rendered by the Rehabilitation Centers available in the community.

Efforts to educate the public about persons with special learning needs is still lacking behind. There is no specific policy on rehabilitation process. A describable way of enlightenment should be adopted for successful identification and treatments, of persons with special needs, since individual with various problems are of different types. Referral of special need person for treatment, education and employment purpose should be made to appropriate places such as hospital, school and government parastatals. There should be provision of special equipments and facilities for effective rehabilitation. The fact that many people have less knowledge about care and treatment of the handicapped. Given proper rehabilitation to special need persons should not be denied upon.

\section{References}

[1]. Andrews, J. R. \& Herrelson, G.L. (1991). Physical rehabilitation of the injured athlete. Mexico: W.B. savders company.

[2]. Carte, E. T., Nigg, J. T. \& Hinshaw S. P. (1996). Neuropsychological Functioning, Motor Speed, and Language Processing in Boys with and without ADHD Journal of Abnormal Child Psychology, 6 (24) $481-498$

[3]. Cratty, B. (1989). Adapted Physical Education in the Mainstream Second schools 2nd edition EagleWood: Love Publishing Company.

[4]. Dunlop, D. (2005). Starting an Exercise Program for High risk Individuals. California: Millipore Health Press.

[5]. Ihenacho, I. J. (2010). The need for effective rehabilitation service delivery. In Ajobiewe \& Osurji (Ed.) New Perspectives in Special Need Education for Sustainable Development National Centre for Exceptional Children (NCEC) Ibadan: Glory-Land Publishing Company. 1-7.

[6]. Physical Medicine and Rehabilitation (2010). Encyclopædia Britannica.

[7]. Encyclopaedia Britannica Student and Home Edition. Chicago: Encyclopædia Britannica.

[8]. Punwar, A. J. (1994). Occupational Therapy. Principle and Practice (Second edition) London: Williams and Wilkins Limited.

[9]. Shivers, J. S. \& Fait, H. F. (1985). Special recreational services therapeutic and adapted. Washington: lea \& febiger Philadelphia. 